уДК 681.62.067.35

\title{
РОЗРАХУНОК ВІДНОВЛЮВАЛЬНОГО МОМЕНТУ І ДОДАТКОВОГО КУЛАЧКА РОЗВАНТАЖУВАЛЬНОГО ПРИСТРОЮ ПРИВОДУ ТАМПОДРУКАРСЬКОЇ МАШИНИ ПТМ-200
}

( О. О. Палюх, к.т.н., доцент, НТУУ «КПІ», Київ, Україна

Как показали проведенные исследования разгружающего устройства привода тампопечатной машины ПТМ-200 для независимого уравновешивания статических и инерционных нагрузок, которые возникают в приводах поворотных столов целесообразно использовать кулачковые механизмы сблокированные с разгружающими устройствами.

As shown by studies unload drive unit tampoprint machine PTM200 is independent of static balance and inertial loads, which arise in the drive rotary tables should be used cam mechanisms interlocked with unload devices.

\section{Постановка проблеми}

Задачею синтезу кулачкових механізмів зблокованих з розвантажувальними пристроями РП є синтез виконавчого механізму (кулачкової пари), якому повинен передувати синтез закону періодичного руху вихідної ланки ВЛ за пружними характеристиками РП.

\section{Аналіз попередніх досліджень}

Особливістю механізмів для реверсивного обертального і поступального руху ВЛ $\epsilon$ нерівномірний рух кулачка. Дослідження показали, що для механізмів періодичного повороту також доцільним $\epsilon$ передача кулачку нерівномірного руху за допомогою приводного механізму, що задає кулачку максимальну кутову швидкість в момент переходу вихідної ланки від розбігу до вибігу. При цьому досягається змен- шення габаритів, розширюється діапазон змін відношення періоду повороту до періоду вистою.

\section{Мета роботи}

Аналіз механізмів періодичного повороту приводів тамподрукарських машин 3 метою їх удосконалення, що дозволяє реалізовувати більш сприятливі закони періодичного руху вихідної ланки.

\section{Результати проведених досліджень}

На ведучому валу I тамподрукарської машини ПтМ-200 (рис. 1) закріплені здвоєні кулаки 1, 2, на які опирається коромисло 3 з роликами 4, 5, геометрично замкнутими на кулаках 1, 2. Коромисло 3 вільно насаджено на ведений вал II і шестерні 6, 7, закріплені на коромислі 3, взаємодіють 3 шестернею 8, веденою вала II і створю- 


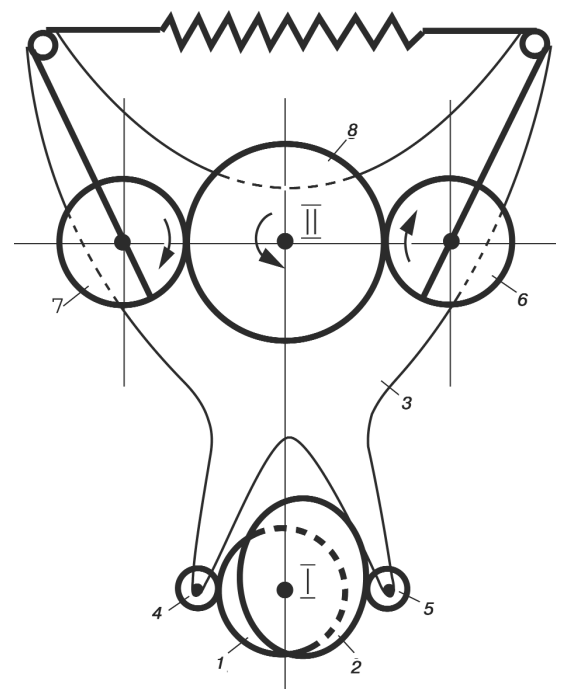

Рис. 1. Схема кулачкового розвантажуючого механізму тамподрукарської машини

ють додатковий момент, який розганяє ведену масу.

- Розрахунок відновлюючого моменту (рис. 2).

$M_{\text {пр }}=P_{\mathrm{i}} \mathrm{h}_{\mathrm{i}}, \quad \mathrm{P}_{\mathrm{i}}=\mathrm{c}\left(\mathrm{S}_{0}+4 \mathrm{r}-2 \mathrm{~S}_{\mathrm{i}}\right)$, $\mathrm{S}_{\mathrm{i}}=(\mathrm{a}+\mathrm{r})-\mathrm{I}_{\mathrm{i}}$

$$
\begin{aligned}
& I_{i}=\sqrt{r^{2}+a^{2}-2 \operatorname{racos}\left(\pi-i \gamma_{i}\right)} \\
& S_{i}=a+r- \\
& -\sqrt{r^{2}+a^{2}-2 \operatorname{racos}\left(\pi-i \gamma_{i}\right)}
\end{aligned}
$$$$
P_{i}=c\left[\begin{array}{l}
S_{0}+4 r-2(a+r- \\
-\sqrt{r^{2}+a^{2}-2 r a \cos \left(\pi-i \gamma_{i}\right)}
\end{array}\right]=
$$$$
=\operatorname{cr}\left[\begin{array}{l}
\chi_{0}+4-2(\lambda+1- \\
\left.-\sqrt{1+\lambda^{2}+2 \lambda \operatorname{cosi} \gamma_{i}}\right)
\end{array}\right] \text {; }
$$$$
P_{i}=c r\left[\begin{array}{l}
\chi_{0}+4-2 \lambda-2+ \\
+2 \sqrt{1+\lambda^{2}+2 \lambda \operatorname{cosi} \gamma_{i}}
\end{array}\right]=
$$$$
=\operatorname{cr}\left[\begin{array}{l}
\chi_{0}+2-2 \lambda+ \\
+2 \sqrt{1+\lambda^{2}+2 \lambda \operatorname{cosi} \gamma_{i}}
\end{array}\right]
$$

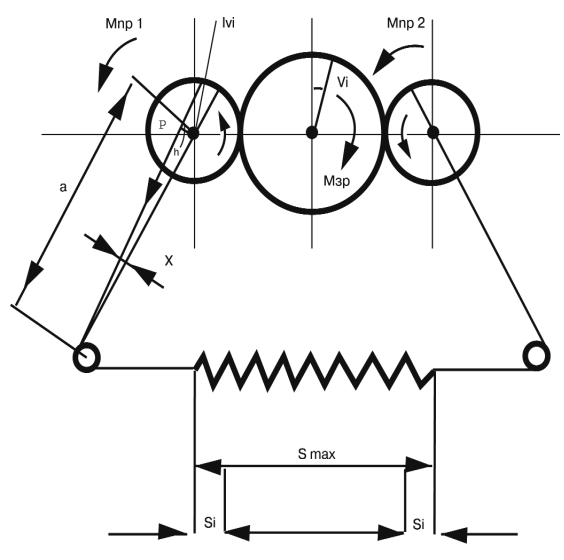

Рис. 2. Схема механізму для розрахунку відновлюючого моменту

$$
\begin{aligned}
& P_{i}=2 \operatorname{cr}\left(0,5 \chi_{0}+1-\lambda+\right. \\
& \left.+\sqrt{1+\lambda^{2}+2 \lambda \operatorname{cosi} \gamma_{i}}\right)
\end{aligned}
$$

$$
\mathrm{h}_{\mathrm{i}}=\operatorname{asin} \psi \text {, }
$$

$$
\begin{aligned}
& \sin \psi=\frac{r \operatorname{sini} \gamma_{i}}{l_{i}}= \\
& =a \frac{\operatorname{sini} \gamma_{i}}{\sqrt{1+\lambda^{2}+2 \lambda \operatorname{cosi} \gamma_{i}}} ;
\end{aligned}
$$

$\mathrm{M}_{\text {пр }}=2 \mathrm{cr}^{2}\left(0,5 \chi_{0}+1-\lambda+\right.$

$\left.+\sqrt{1+\lambda^{2}+2 \lambda \operatorname{cosi} \gamma_{i}}\right) \times$

$\times \frac{\lambda \operatorname{sini} \gamma_{i}}{\sqrt{1+\lambda^{2}+2 \lambda \operatorname{cosi} \gamma_{i}}}=$

$=2 \operatorname{cr}^{2}\left(1+\frac{0,5 \chi_{0}+1-\lambda}{\sqrt{1+\lambda^{2}+2 \lambda \operatorname{cosi} \gamma_{i}}}\right) \times$

$\times \lambda \operatorname{sini} \gamma_{i} ;$

$$
\begin{aligned}
& \mathrm{M}_{\mathrm{yp \Sigma}}=4 \mathrm{cr}^{2} \lambda \operatorname{sini} \gamma_{\mathrm{i}} \times \\
& \times\left(1+\frac{0,5 \chi_{0}+1-\lambda}{\sqrt{1+\lambda^{2}+2 \lambda \operatorname{cosi} \gamma_{i}}}\right)
\end{aligned}
$$




$$
\begin{array}{r}
i=2 \\
M_{y p \Sigma}=i M_{n p \Sigma}=8 \mathrm{cr}^{2} \lambda \sin 2 \gamma_{i} \times \\
\quad\left(1+\frac{0,5 \chi_{0}+1-\lambda}{\sqrt{1+\lambda^{2}+2 \lambda \cos 2 \gamma_{i}}}\right) .
\end{array}
$$
кулачка.

- Розрахунок додаткового

В початковому положенні (період розбігу) пружина повинна мати початковий момент для розгону маси. Для цього під час вистою додатковий блок кулачків повертає коромисло 3 на кут $\pi / 20$ по заданому закону pyxy.

Шестерні 7, 6 повертаються на кут (i $\pi / 20=\pi / 10)$ і створюють необхідний додатковий момент. На ділянці $0 \leq \mathrm{a}_{\mathrm{k}} \leq 0,25\left(\gamma_{\mathrm{i}}=2 \pi \mathrm{a}_{\mathrm{k}}+\right.$ $+\pi / 10)-$ момент доходить до максимуму, а на ділянці $0,25 \leq$ $\leq a_{k} \leq 0,5\left(\gamma_{i}=2 \pi a_{k}+\pi / 10+\right.$ $+\pi / 10 \cos 2 \pi \mathrm{a}_{\mathrm{k}}$ ) момент 3 максимуму зменшується до 0. Таким чином блок кулачків повертає коромисло із шестернями у вихідне положення.

На ділянці 0,5 $\leq \mathrm{a}_{\mathrm{k}} \leq 0,75\left(\gamma_{\mathrm{i}}=\right.$ $\left.=2 \pi a_{k}-\pi / 10\left(1+\cos 2 \pi a_{k}\right)\right)$ момент зростає від 0 до максимуму, а шестерні повертаються в протилежну від розбігу сторону. На ділянці $0,75 \leq \mathrm{a}_{\mathrm{k}} \leq 1 \quad\left(\gamma_{\mathrm{i}}=\right.$ $=2 \pi \mathrm{a}_{\mathrm{k}}-\pi / 10$ ) момент зменшується від максимуму до від'ємного додаткового моменту, переміна знака, якого здійснюється під час вистою.

- Визначення комплексного інваріанта переміщення $a_{k}$ додаткового кулака.

Ділянка $0 \leq \mathrm{a}_{\mathrm{k}} \leq 0,25$

$$
\gamma_{i}=i \gamma^{\prime}+\gamma_{\Sigma}^{\prime \prime} / 2 ; \quad \gamma^{\prime}=\gamma_{\Sigma}^{\prime} a_{k}=\pi a_{k}
$$

$$
\begin{gathered}
a_{k}=\frac{2 \pi k-\sin 2 \pi k}{2 \pi} " c_{0} " ; \\
\gamma_{i}=2 \pi a_{k}+\pi / 10 ; \gamma_{\Sigma}=\pi / 10 . \\
\text { Ділянка } 0,25 \leq a_{k} \leq 0,5 \\
\gamma_{i}=i \gamma^{\prime}+i \gamma_{\Sigma}^{\prime \prime} a_{k 1} ; a_{k 1}=\frac{1+\cos 2 \pi a_{k}}{2} ; \\
\gamma_{i}=2 \pi a_{k}+\pi / 10\left(1+\cos 2 \pi a_{k}\right) . \\
\text { Ділянка 0,5 } \leq a_{k} \leq 0,75 \\
\gamma_{i}=i \gamma^{\prime}+i \gamma_{\Sigma}^{\prime \prime} a_{k 1} ; a_{k 1}=-\frac{1+\cos 2 \pi a_{k}}{2} ; \\
\gamma_{i}=2 \pi a_{k}+\pi / 10\left(1+\cos 2 \pi a_{k}\right) .
\end{gathered}
$$

Ділянка 0,75 $\leq \mathrm{a}_{\mathrm{k}} \leq 1$ $\gamma_{i}=i \gamma^{\prime}-i \gamma_{\Sigma}^{\prime \prime} / 2 ; \quad \gamma_{i}=2 \pi a_{k}+\pi / 10$

- Визначення радіусів-векторів додаткового кулака

$$
\begin{gathered}
r=\sqrt{l^{2}+b^{2}-2 b l \cos \left(\gamma_{0}^{\prime \prime}+\gamma_{\Sigma}^{\prime \prime} a_{k 1}\right)} \\
r_{k}=\frac{r}{I} \sqrt{1+\beta^{2}-2 \beta \cos \left(\gamma_{0}^{\prime \prime}+\gamma_{\Sigma}^{\prime \prime} a_{k 1}\right)},
\end{gathered}
$$

де I - базова відстань, I = = 166,5 мм; b - довжина коромисла, $\mathrm{b}=140 \mathrm{мM} ; \quad \beta=\frac{\mathrm{b}}{\mathrm{l}}=\frac{140}{166,5}=$ $=0,84$; приймаємо $\gamma_{0}^{\prime \prime}=30^{\circ}$.

Ділянка 0,25 $\leq \mathrm{a}_{\mathrm{k}} \leq 0,5$ при $\mathrm{a}_{\mathrm{k}}=0,25, \mathrm{a}_{\mathrm{k} 1}=0,5$

$$
\begin{aligned}
r_{k} & =\sqrt{1+\beta^{2}-2 \beta \cos \left(\gamma_{0}^{\prime \prime}+\gamma_{\Sigma}^{\prime \prime} 0,5\right)}= \\
& =\sqrt{1+0,84^{2}-2 \cdot 0,84 \cos 39^{0}}= \\
& =0,634,
\end{aligned}
$$

$$
\begin{aligned}
& r=r_{k l}=0,634 \cdot 166,5 \approx 105 \mathrm{MM}, \\
& r=r_{k l}=0,355 \cdot 166,5 \approx 59,5 \mathrm{MM} .
\end{aligned}
$$$$
\text { при } \mathrm{a}_{\mathrm{k}}=0,5, \mathrm{a}_{\mathrm{k} 1}=0
$$

$$
\begin{aligned}
r_{k} & =\sqrt{1+\beta^{2}-2 \beta \cos \left(\gamma_{0}^{\prime \prime}+\gamma_{\Sigma}^{\prime \prime} \cdot 0\right)}= \\
& =\sqrt{1+0,84^{2}-2 \cdot 0,84 \cos 30^{\circ}}= \\
& =0,495,
\end{aligned}
$$


$\mathrm{r}=\mathrm{rkl}_{\mathrm{kl}}=0,495 \cdot 166,5 \approx 82,5 \mathrm{M}$.

Ділянка 0,5 $\leq \mathrm{a}_{\mathrm{k}} \leq 0,75$

при $\mathrm{a}_{\mathrm{k}}=0,75, \mathrm{a}_{\mathrm{k} 1}=-0,5$

$r_{k}=\sqrt{1+\beta^{2}-2 \beta \cos \left(\gamma_{0}^{\prime \prime}+\gamma_{\Sigma}^{\prime \prime}(-0,5)\right.}=$

$=\sqrt{1+0,84^{2}-2 \cdot 0,84 \cos 21^{0}}=$

$=0,355$,

$\mathrm{r}=\mathrm{rkl}_{\mathrm{kl}}=0,355 \cdot 166,5 \approx 59,5 \mathrm{Mm}$.

\section{Висновки}

Як показали проведені дослідження, реалізація технологічних процесів друкування на тамподрукарських машинах 3 врахуванням різноманітної номенклатури продукції, що випус- кається, обумовлює необхідність експлуатації цих машин у швидкісному діапазоні.

Для незалежного зрівноваження надлишкових статичних та інерційних навантажень, що виникають у приводах обертових столів тамподрукарських машин, доцільно використовувати кулачкові механізми, зблоковані з розвантажуючими пристроями, які мають переваги у можливості використання безударних законів вихідних ланок, відсутності змінної структури та ефективності застосування розвантажуючих пристроїв.

1. Вульфсон И. И. Динамические расчеты цикловых механизмов / И. И. Вульфсон. - Л. : Машиностроение, 1976. - 328 с. 2. Мордовин Б. М. Методы расчета цикличностей / Б. М. Мордовин. - Учеб. пос. - М. : МПИ, 1978. 3. Нахапетян Е. Г. Транспортные устройства автоматов, встраиваемых в автоматические линии / Е. Г. Нахапетян. - М. : Наука, 1977. - 136 с. 4. Новгородцев В. А. Дифференциальные кулачково-зубчатые механизмы периодического поворота / В. А. Новгородцев, М. Е. Фишин. - В кн. : Теория механизмов и машин. - Харьков : ХГУ, 1975. - вып. 18. - С. 102-109. 5. Палюх А. А. Улучшение качественных характеристик поворотных кулачковых механизмов для привода транспортирующих устройств полиграфических машин / А. А. Палюх. - В кн. : II Всесоюзная конференция молодых ученых и специалистов Госкомпечати СССР : Тез. докл. - Телави, 1990. 6. Палюх А. А. Параметрические исследования кулачковых поворотных механизмов / А. А. Палюх. - В кн. : IX Всесоюзная научно-техническая конференция по специальным видам печати : Тез. докл. - Киев, 1990. 7. Палюх О. О. Механізми періодичного руху та рекомендації по їх застосуванню в поліграфічних машинах / А. А. Палюх. - Методичні вказівки. - Київ : Національний технічний університет України «Київський політехнічний інститут», 1995. - 52 с.

1. . Vul'fson I. I. Dinamicheskie raschety ciklovyh mehanizmov / I. I. Vul'fson. - L., Mashinostroenie, 1976. - 328 s. 2. Mordovin B. M. Metody rascheta ciklichnostej / B. M. Mordovin. - Ucheb. pos. - M. : MPI, 1978. 3. Nahapetjan E. G. Transportnye ustrojstva avtomatov, vstraivaemyh v avtomaticheskie linii / E. G. Nahapetjan. - M. : Nauka, 1977. - 136 s. 4. Novgorodcev V. A. Differencial'nye kulachkovo-zubchatye mehanizmy periodicheskogo povorota / V. A. Novgorodcev, M. E. Fishin. - V kn. : Teorija mehanizmov i mashin. - Har'kov : HGU, 1975. - vyp. 18. - S. 102-109. 5. Paljuh A. A. Uluchshenie kachestvennyh harakteristik povorotnyh 
kulachkovyh mehanizmov dlja privoda transportirujushhih ustrojstv poligraficheskih mashin / A. A. Paljuh. - V kn. : II Vsesojuznaja konferencija molodyh uchenyh i specialistov Goskompechati SSSR : Tez. dokl. - Telavi, 1990. 6. Paljuh A. A. Parametricheskie issledovanija kulachkovyh povorotnyh mehanizmov / A. A. Paljuh. — V kn. : IH Vsesojuznaja nauchno-tehnicheskaja konferencija po special'nym vidam pechati : Tez. dokl. - Kiev, 1990. 7. Paliukh O. O. Mekhanizmy periodychnoho rukhu ta rekomendatsii po yikh zastosuvanniu $v$ polihrafichnykh mashynakh / A. A. Paliukh. - Metodychni vkazivky. - Kyiv : Natsionalnyi tekhnichnyi universytet Ukrainy «Kyivskyi politekhnichnyi instytut», 1995. - $52 \mathrm{~s}$.

$$
\begin{array}{r}
\text { Рецензент - Ю. О. Шостачук, к.т.н., } \\
\text { доцент, НТУУ «КПІ» }
\end{array}
$$

Надійшла до редакції 14.09.12 